\title{
ANALISIS SWOT PENGOLAHAN MAKANAN PADA KATERING \\ DI KECAMATAN SIMOKERTO TAHUN 2019
}

Sharen Liestya Santosa, Narwati, Ernita Sari

Jurusan Kesehatan Lingkungan Poltekkes Kemenkes Surabaya

Email : sharenliestyas@gmail.com

\begin{abstract}
Jasaboga in producing food must pay attention to the quality of food to improve food quality need to process food that is in accordance with the requirements of food sanitation hygiene. So the purpose of this study is to assess the application of food processing to catering in Simokerto Subdistrict where the components of food processing such as food processing, food processing, food equipment, and food handlers are then analyzed using SWOT Analysis (Strength, Weakness, Opportunity, and Threats). The results of the SWOT analysis will produce a Food Processing Development Strategy for Catering.

This research is descriptive with research design using evaluation design with the aim of the results of this study used for improvement or improvement of activities / programs in catering. The location of the study was carried out in 3 catering in Surabaya Simokerto sub-district, using sampling techniques Total Sampling Technique. The research activity used an observation sheet to obtain data on the application of food processing at the catering district of Simokerto Surabaya.

Based on the results of the study, Food Processing catering in Simokerto Surabaya District in general is good and according to existing regulations such as Food Processing Places has a Good category of $78 \%$, Food Processing has a Good category of $67 \%$, Food Handlers have a Good category of $72 \%$ while Cookware has a sufficient category of $64 \%$ so that repairs need to be done. In improving catering food processing can be done by utilizing the strengths and opportunities that exist among them by conducting routine monitoring of the health center, counseling on food safety and food processing methods that are good and right, and for catering in Simokerto sub-district can implement the recommended development strategy to innovate on a variety of menus to increase consumer purchasing power, take advantage of technological advance as a media for promotion and register catering to health services to obtain Jasaboga sanitary hygiene certificates.
\end{abstract}

Keywords : Food processing, SWOT Analysis and Food Processing development strategy

\section{PENDAHULUAN}

Seiring bertambahnya kemajuan zaman, banyak masyarakat di Surabaya yang tidak sempat menyiapkan sendiri makanan yang akan mereka konsumsi. Masyarakat bergantung pada pelayanan usaha makanan, salah satunya yaitu Jasaboga, untuk memenuhi kebutuhan makanan mereka. Menurut PERMENKES Nomor 1096 Tahun 2011, Jasaboga merupakan satu bangunan yang digunakan untuk pengolahan makanan yang akan disajikan untuk memenuhi kebutuhan masyarakat umum yang didasarkan atas pesanan yang dilakukan oleh perseorangan atau badan usaha.

Jasaboga dalam menghasilkan makanan harus memperhatikan kualitas makanan agar tidak mengandung mikroorganisme, dan bahan-bahan lain yang dapat menimbulkan bahaya bagi konsumen sehingga dibutuhkan suatu usaha penyehatan makanan dan minuman. Upaya pengendalian perlu dilakukan untuk menghasilkan makanan 
yang aman dikonsumsi dan terbebas dari segala bentuk kontaminasi makanan.

Menurut data sekunder Dinas Kesehatan Kota bahwa keracunan makanan di Kecamatan Simokerto di akibatkan oleh nasi kotak yang di produksi oleh jasaboga. Dari hasil observasi hal ini disebabkan karena jasaboga di wilayah Simokerto belum menerapkan Higiene Sanitasi Makanan sebagaimana yang di atur dalam PERMENKES Nomor 1096 tahun 2011.

Untuk meningkatkan kualitas pengolahan makanan katering di Kecamatan Simokerto, dibutuhkan strategi untuk memperbaikinya. Salah satu strategi yang dapat dilakukan yaitu dengan menggunakan strategi Analisis SWOT. Menurut Freddy (2008), Analisis SWOT merupakan strategi perencanaan yang digunakan untuk menganalisis faktor Strength (kekuatan), Weakness (kelemahan), Opportunity (peluang), dan Threats (ancaman) dalam suatu perusahaan untuk pengambilan keputusan strategi yang berkaitan dengan pengembangan.

Tujuan dari penelitian ini adalah Mengetahui penerapan Pengolahan Makanan Katering di Kecamatan Simokerto Surabaya.

\section{METODE PENELITIAN}

Jenis penelitian ini menggunakan metode penelitian deskriptif yaitu metode yang dilakukan dengan tujuan utama untuk menggambarkan tentang suatu keadaan secara obyektif, yang dilakukan dengan survei penilaian terhadap beberapa variabel. Jumlah sampel dalam penelitian ini yaitu 3 sampel katering di Kecamatan Simokerto Surabaya. Teknik pengambilan sampel menggunakan Total Sampling.

Variabel dalam Penelitian ini adalah Tempat pengolahan makanan, Cara pengolahan makanan, Peralatan masak, dan Penjamah makanan. Teknik pengumpulan data menggunakan lembar observasi kemudian dilakukan observasi pada 3 katering di kecamatan Simokerto Surabaya.

\section{HASIL DAN PEMBAHASAN Pengolahan Makanan pada Katering}

1. Tempat Pengolahan makanan

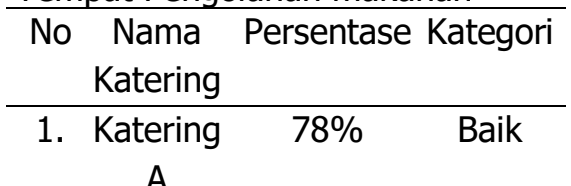

2. Katering $89 \% \quad$ Baik

B

3. Katering $72 \%$ Baik

C

Secara keseluruhan penilaian
Tempat pengolahan makanan mendapatkan hasil sebesar $78 \%$ yaitu memiliki kualitas tempat pengolahan makanan yang baik. Dari 18 kriteria yang dinilai terdapat 16 kriteria yang memiliki kriteria baik dan 2 kriteria yang memiliki kategori cukup dari ketiga katering tersebut. Kriteria yang dinilai masih kurang yaitu pada kriteria lokasi jasaboga yang masih berdekatan dengan sumber pencemar nilai yang di dapat yaitu (34\%) hal ini terdapat pada Katering $A$ dan Katering B Kemudian pada kriteria jarak saluran pembuangan air limbah ke sumber air bersih masih kurang dari 10 meter nilai yang diperoleh yaitu (34\%) hal ini terdapat pada Katering A dan Katering B. Menurut penelitian Marylin,dkk (2008), diperoleh hasil bahwa ada hubungan kondisi tempat pembuangan sampah sementara dengan kejadian diare. Hal ini berpotensi menyebabkan diare karena saat lalat yang mencari makan di sampah yang tidak tertutup terbang ke dapur kemudian akan hinggap di makanan yang tidak ditutup oleh penjamah makanan.

Berdasarkan hasil observasi pada katering $\mathrm{C}$ memiliki bukaan ventilasi jendela dan pintu yang kurang efisien. Menurut Victa, Hery, Anik (2015), ventilasi juga dapat membantu sirkulasi udara agar ruangan tidak pengap. Artinya suasana tempat pengolahan makanan menghasilkan suhu lebih tinggi dan uap panas, serta asap dalam jumlah banyak sehingga ventilasi yang kurang dapat menyebabkan meningkatnya jumlah karbondioksida dan lembab. 
Setelah melakukan observasi setiap katering sudah memiliki jamban yang cukup untuk karyawan yaitu 1 jamban leher angsa setiap 10 orang didalam rumah. Setelah melakukan observasi keadaan air bersih yang digunakan dalam mengolah makanan tidak berbau dan tidak berwarna hal ini dapat diketahui karena katering di kecamatan Simokerto sudah menggunakan air PDAM yang telah melalui tahap pemeriksaan lengkap yaitu uji fisik, kimia dan biologis.

2. Cara Pengolahan Makan

\begin{tabular}{ccc}
\hline No $\begin{array}{c}\text { Nama } \\
\text { Katering }\end{array}$ & Persentase Kategori \\
\hline 1. Katering & $75 \%$ & Baik \\
A & & \\
2. Katering & $67 \%$ & Cukup \\
B & & \\
3. Katering & $58 \%$ & Cukup \\
C & & \\
\hline
\end{tabular}

Secara keseluruhan penilaian Cara Pengolahan Makanan mendapatkan hasil sebesar $67 \%$ yaitu memiliki kualitas cara pengolahan makanan yang baik. Dari 12 kriteria yang dinilai terdapat 9 kriteria yang memiliki kriteria baik, 1 kriteria yang memiliki kategori cukup, dan 2 kriteria yang memiliki kategori kurang dari ketiga katering tersebut.

Kriteria yang dinilai masih kurang yaitu pada kriteria masih terjadi pengotoran fisik/kontaminasi makanan, nilai yang di dapat yaitu (34\%) hal ini terdapat pada Katering C. Pada kriteria makanan masih mengandung cemaran bakteri Escherichia coli, nilai yang diperoleh yaitu $(0 \%)$ hal ini terdapat pada ketiga katering. Pada kriteria masih menempatkan makanan terbuka dengan tumpang tindih, nilai yang diperoleh yaitu $(0 \%)$ hal ini terdapat diketiga katering. Setelah melakukan observasi terdapat katering yang menggunakan tangan dalam menjamah makanan yang sudah masak tidak menggunakan sendok atau penjepit.

3. Peralatan Masak

No Nama Persentase Kategori
Katering

\begin{tabular}{ccc}
\hline $\begin{array}{c}\text { 1. Katering } \\
\text { A }\end{array}$ & $60 \%$ & Cukup \\
$\begin{array}{ccc}\text { 2. Katering } \\
\text { B }\end{array}$ & $67 \%$ & Cukup \\
$\begin{array}{c}\text { 3. Katering } \\
\text { C }\end{array}$ & $67 \%$ & Cukup \\
\hline
\end{tabular}

Secara keseluruhan penilaian Peralatan Masak mendapatkan hasil sebesar $64 \%$ yaitu memiliki kualitas peralatan masak yang cukup. Dari 15 kriteria yang dinilai terdapat 9 kriteria yang memiliki kategori baik, dan 6 kriteria yang memiliki kategori kurang dari ketiga katering tersebut. Kriteria yang dinilai masih kurang yaitu pada kriteria masih menggunaka talenan yang terbuat dari bahan kayu, nilai yang di dapat yaitu (33\%) hal ini terdapat pada Katering B dan Katering C. Pada kriteria meja peracikan makanan tidak dijaga kebersihannya, nilai yang diperoleh yaitu (0\%) hal ini terdapat pada ketiga katering. Pada kriteria meja peracikan makanan tidak kuat, nilai yang diperoleh yaitu $(0 \%)$ hal ini terdapat diketiga katering. Pada kriteria tidak membedakan antara peralatan untuk mengolah bahan mentah dan peralatan untuk mengolah makanan yang sudah masak, nilai yang diperoleh yaitu $(33 \%)$ hal ini terdapat pada Katering $A$ dan Katering B. Pada kriteria masih terdapat cemaran bakteri Escherichia coli pada peralatan masak, nilai yang diperoleh yaitu $(0 \%)$ hal ini terdapat pada ketiga katering terebut.

Kemudian setelah melakukan observasi pada katering $A$, katering $B$ dan katering $C$ belum mempunyai meja peracikan dikarenakan terbatasnya luas dapur, hal ini dapat berpotensi terkontaminasi karena meracik di lantai yang tidak terjaga kebersihannya seperti pada komponen tempat pengolahan makanan yang masih terdapat katering yang memiliki lantai yang tidak bersih. Hal ini dapat berhubungan dengan hasil laboratorium menunjukkan makanan yang dihasilkan katering positif mengandung bakteri Escherichia coli karena Katering yang tidak memiliki meja 
peracikan dalam menyiapkan makanan pasti akan meracik makanannya di lantai.

4. Penjamah Makanan

\begin{tabular}{ccc}
\hline No Nama PersentaseKategori \\
Katering & & \\
\hline $\begin{array}{c}\text { 1. Katering } \\
\text { A }\end{array}$ & $66 \%$ & Cukup \\
2. Katering & $75 \%$ & Baik \\
B & & \\
3. Katering & $75 \%$ & Baik \\
C & & \\
\end{tabular}

Secara keseluruhan penilaian Penjamah makanan mendapatkan hasil sebesar $72 \%$ yaitu memiliki kualitas penjamah makanan yang Baik. Dari 12 kriteria yang dinilai terdapat 9 kriteria yang memiliki kategori baik, dan 3 kriteria yang memiliki kategori kurang dari ketiga katering tersebut. Kriteria yang dinilai masih kurang yaitu pada kriteria penjamah makanan masih belum memiliki sertifikat kursus higiene sanitasi makanan, nilai yang di dapat yaitu (33\%) hal ini terdapat pada Katering B dan Katering C. Pada kriteria berbadan sehat dengan menunjukkan surat keterangan sehat, nilai yang diperoleh yaitu (33\%) hal ini hanya terdapat pada Katering $A$. Pada kriteria tidak menggunakan pelindung cemaran, nilai yang diperoleh yaitu $(0 \%)$ hal ini terdapat diketiga katering.

Setelah melakukan observasi ditemukan Penjamah Makanan pada pada Katering B dan Katering $\mathrm{C}$ masih belum memiliki sertifikat kursus Higiene Sanitasi Makanan, hal ini dikarena pengelola masih belum mengurus surat medaftaran jasaboga di Dinas Kesehatan Kota Surabaya.

Dari keseluruhan penjamah makanan di ketiga katering, setelah melakukan observasi masih terdapat penjamah makanan yang tidak memakai alat pelindung cemaran seperti celemek dan penutup kepala. Penggunaan celemek dan penutup kepala saat mengolah juga perlu dilakukan guna mencegah pakaian yang tidak rapi mengenai makanan yang sedang diolah. Hal ini tidak sesuai dengan pernyataan Depkes (2001), bahwa pakaian yang tidak bersih mengandung banyak debu dan sebelum digunakan sebaiknya pakaian yang akan digunakan untuk bekerja harus di setrika terlebih dahulu untuk meminimalisir keberadaan bakteri dengan panas setrika.

5. Kualitas makanan pada katering di Kecamatan Simokerto Surabaya Menurut persyaratan kualitas bakteri Escherichia coli pada makanan yang diproduksi oleh katering mengacu pada Peraturan Menteri Kesehatan Republik Indonesia Nomor 1096 tahun 2011 tentang Higiene Sanitasi Jasaboga bahwa makanan yang diproduksi harus tidak ada bakteri Escherichia coli atau harus 0 CFU/gr. Beberapa contoh makanan yang dilakukan pemeriksaan laboratorium yaitu Oseng-oseng kerang, Sayur Bening, dan Tahu Goreng.

Keberadaan bakteri dalam tahu goreng dapat disebabkan karena saat dilakukan observasi tahu goreng dibiarkan dalam kondisi terbuka saat sudah matang, saat penjamah mengepak makanan di dalam tepak makan tidak menggunaan sarung tangan melainkan hanya menggunakan tangan tanpa menggunakan penjepit makan. Hal ini dapat mempengaruhi cemaran dalam tahu karena makanan yang tidak tertutup dapat dihinggapi lalat dan terbukti saat observasi didalam ruang pengolahan masih terdapat lalat yang berterbangan karena kondisi dapur yang tidak bersih. Kemudian bila penjamah tidak menggunakan alat pelindung saat kontak langsung dengan masyarakat juga mempengaruhi karena saat memegang tahu goreng dengan tangan penjamah belum tentu terjaga kebersihannya seperti dalam Depkes RI (2001) menyatakan kebersihan tangan sangat penting bagi setiap orang terutaa penjamah makanan.

6. Kualitas Peralatan Masak pada katering di Kecamatan Simokerto Surabaya

Proses pencucian peralatan masak mempengaruhi dari jumlah bakteri yang terkandung dalam permukaan peralatan. Pada saat pencucian tidak dilakukan dengan baik dan benar maka akan terjadi resiko kontaminasi dari sisa makanan yang ada di alat masak. 
Pencucian harus menggunakan sabun atau desinfektan agar bakteri dapat hilang dengan bahan kimia yang terdapat di sabun. Teknik pencucian harus dilakukan dengan air yang mengalir, menggunakan sabun/detergen, menghilangkan sisa makanan yang menempel pada permukaan peralatan masak.

7. Kualitas Air Bersih pada katering di Kecamatan Simokerto Surabaya

Menurut persyaratan kualitas

bakteri Escherichia coli air bersih untuk keperluan higiene sanitasi mengacu pada Peraturan Menteri Kesehatan Republik Indonesia Nomor 31 tahun 2017 tentang Standar Baku Mutu Kesehatan Lingkungan dan Persyaratan Kesehatan Air untuk keperluan Higiene Sanitasi, Kolam renang, Solus per Aqua, dan Pemandian umum sanitasi bahwa tiap air bersih yang digunakan untuk parameter Escherichia coli mempunyai kadar maksimum sebesar $0 \mathrm{CFU} / \mathrm{ml}$.

Sumber air bersih yang digunakan selama mengolah makanan di katering kecamatan Simokerto Surabaya menggunakan air PDAM. berdasarkan hasil pemeriksaan laboratorium diketahui bahwa kualitas bakteri Escherichia coli air bersih yang digunakan selama mengolah makanan oleh katering di kecamatan Simokerto Surabaya didapatkan hasil sebesar $0 \quad \mathrm{CFU} / \mathrm{ml}$ sehingga dapat dikatakan kualitas air bersih memenuhi syarat karena tidak melebihi kadar maksimum yang sudah ditetapkan untuk kebutuhan higiene sanitasi adalah 0 $\mathrm{CFU} / \mathrm{ml}$. Berarti kualitas air bersih yang digunakan selama mengolah makanan dikatakan aman untuk digunakan karena hasil pemeriksaan untuk parameter Escherichia coli menunjukkan tidak melebihi kadar maksimum.

\section{B. Strategi Pengembangan Pengolahan Makanan Katering di Kecamatan Simokerto Surabaya}

1. Strategi Pengembangan pada Katering $A$

Berdasarkan perhitungan dan posisi relatif Pengolahan Makanan pada Katering A berada di kuadran I (Aggressive) dengan titik koordinat $X=0,56$ dan $Y=0,28$. Kuadran aggressive artinya Pengolahan makanan pada Katering A dalam kondisi baik maka sangat dimungkinkan untuk terus melakukan pengembangan usaha maupun membuka cabang kedua sehingga dapat memperbesar pertumbuhan katering dan meraih kemajuan secara maksimal dengan lebih dikenal oleh masyarakat.

Posisi strategi pengembangan pada kuadran I ialah Strategi S-O. Strategi S-O adalah strategi yang menggunakan kekuatan untuk memanfaatkan peluang.

Rekomendasi Strategi pengembangan S-O atau Strength Opportunity yang dapat di lakukan yaitu dengan Menjaga kualitas yang sudah baik dalam pengolahan makanan agar dapat lebih meningkatkan kemampuan daya beli konsumen sehingga katering dapat lebih dikenal oleh masyarakat luas.

2. Strategi Pengembangan pada Katering B

Berdasarkan perhitungan dan posisi relatif Pengolahan Makanan pada Katering $\mathrm{B}$ berada di kuadran I (Aggressive) dengan titik koordinat $X=0,19$ dan $Y=0,15$. Kuadran aggresive artinya Pengolahan makanan pada Katering B dalam kondisi baik maka sangat dimungkinkan untuk terus melakukan pengembangan usaha maupun membuka cabang kedua sehingga dapat memperbesar pertumbuhan katering dan meraih kemajuan secara maksimal dengan lebih dikenal oleh masyarakat.

Posisi strategi pengembangan pada kuadran I ialah Strategi S-O. Strategi S-O adalah strategi yang menggunakan kekuatan untuk memanfaatkan peluang. Rekomendasi Strategi pengembangan S-O atau Strength Opportunity yang dapat di lakukan yaitu Menjaga kualitas yang sudah baik dalam pengolahan makanan agar lebih meningkatkan kemampuan daya beli konsumen dengan cara memperbaiki dan mengevaluasi kekurangan dalam 
pengolahan makanan. Selain itu dapat memanfaatkan bertambahkan penduduk dengan meningkatkan kualitas makanan dan lebih berinovasi terhadap berbagai macam menu agar dapat menarik perhatian konsumen.

3. Strategi Pengembangan pada Katering $C$

Berdasarkan perhitungan dan posisi relatif Pengolahan Makanan pada Katering $\mathrm{C}$ berada di kuadran III (Turn Around) dengan titik koordinat $\mathrm{X}=-2,01$ dan $\mathrm{Y}=0,35$. Kuadran Turn Around artinya Pengolahan makanan pada Katering C dalam kondisi tidak baik maka sangat memungkinkan seiring berjalannya waktu dapat menurunkan kualitas Katering C karena pada proses pengolahan makanannya masih banyak kelemahan yang dilakukan dan juga akan berdampak pada hasil produk makanan yang dihasilkan. Posisi strategi pengembangan pada kuadran III ialah Strategi W-O. Strategi W-O adalah strategi yang dapat memperkecil kelemahan dalam faktor Internal dengan memanfaatkan Peluang dalam faktor eksternal.

Rekomendasi Strategi pengembangan $\mathrm{W}-\mathrm{O}$ atau Weakness - Opportunity yang dapat di lakukan yaitu Dengan adanya kemajuan teknologi dapat memasang perangkap serangga (flytrap). Hal ini penting karena kondisi dapur tidak boleh terdapat serangga dan hewan pengerat karena dapat mempengaruhi kualitas makanan.

\section{KESIMPULAN}

1. Hasil rekapituasi Tempat Pengolahan Makanan di katering A, katering $B$, dan katering $C$ di Kecamatan Simokerto Surabaya menunjukkan kategori nilai Baik yaitu $78 \%$

2. Hasil rekapitulasi Cara Pengolahan Makanan di katering katering $A$, katering $\mathrm{B}$, dan katering $\mathrm{C}$ di Kecamatan Simokerto Surabaya menunjukkan kategori nilai Baik yaitu $67 \%$

3. Hasil rekapitulasi Peralatan Masak di katering katering $A$, katering $B$, dan katering $\mathrm{C}$ di Kecamatan Simokerto Surabaya menunjukkan kategori Cukup yaitu 64\%

4. Hasil rekapitulasi Penjamah Makanan dikatering katering $\mathrm{A}$, katering B, dan katering C di Kecamatan Simokerto Surabaya menunjukkan kategori Baik yaitu $72 \%$

5. Kualitas makanan hasil produk katering di Kecamatan Simokerto Surabaya masih mengalami pencemaran bakteri Escherichia coli pada makanan oseng-oseng kerang, sayur bening dan tahu goreng.

6. Kualitas air bersih yang digunakan mengolah makanan pada katering A, katering $B$ dan Katering $C$ di Kecamatan Simokerto Surabaya tidak mengalami pencemaran bakteri Escherichia coli

7. Kualitas peralatan masak yang digunakan mengolah makanan di katering $A$, katering $B$ dan katering $C$ di Kecamatan Simokerto Surabaya masih mengalami pencemaran bakteri Escherichia coli pada peralatan pisau, talenan dan panci

8. Posisi relatif pada katering $A$ dan katering B berada pada kuadran I yaitu (Aggressive) sehingga strategi pengembangan yang sesuai yaitu strategi Strength-Opportunity. Kemudian rekomendasi Strategi Pengembangan yang dapat di terapkan pada Katering $\mathrm{A}$ dan Katering $B$ yaitu :

a. Menjaga kualitas yang sudah cukup baik dalam pengolahan makanan agar dapat lebih meningkatkan kemampuan daya beli konsumen

b. Dengan bertambahkan penduduk dapat meningkatkan kualitas makanan dan lebih berinovasi terhadap berbagai macam menu agar dapat menarik perhatian konsumen 
c. Dengan adanya perkembangan kemajuan teknologi internet/komunikasi dapat digunakan sebagai media promosi dan pendukung

d. Meningkatkan kapasitas produksi yang disertai dengan keunggulan kualitas pelayanan dan pengolahan makanan karena dengan adanya peningkatan daya beli masyarakat

e. Pemanfaatan kemajuan
teknologi untuk meningkatkan mutu pengolahan makanan dan pelayanan terhadap konsumen

9. Posisi relatif pada katering $\mathrm{C}$ berada pada kuadran III yaitu (Turn Around) sehingga strategi pengembangan yang sesuai yaitu strategi Weakness-Opportunity. Kemudian rekomendasi Strategi Pengembangan yang dapat di terapkan pada Katering $\mathrm{C}$ yaitu :

a. Dengan adanya kemajuan teknologi dapat memasang perangkap serangga (flytrap)

b. Memanfaatkan peningkatan kebutuhan masyarakat Katering C dapat melakukan perbaikan kualitas makanan dengan cara mengevaluasi kelemahan yang ada seperti menggunakan pelindung cemaran (celemek dan penutup kepala), mulai menggunakan perlindung saat kontak langsung dengan makanan, membiasakan menutup makanan matang dengan penutup untuk menghindari hinggapnya vektor penyakit.

c. Pemilik Katering C dapat mendaftarkan segera usahanya di Dinas Kesehatan karena dengan adanya laju pertumbuhan ekonomi yang semakin meningkat setiap tahunnya untuk mendapatkan sertifikat Laik Higiene sanitasi Jasaboga

d. Pemilik Katering C dapat memperbaiki kualitas hasil produk mereka dengan menjaga kebersihan agar tidak tercemar kemudian membuat inovasi menu baru untuk menarik perhatian konsumen.

e. Memperbaiki segera sistem penyimpanan peralatan masak agar tidak mengandung cemaran bakteri dengan memperbarui tempat penyimpanan peralatan karena laju pertumbuhan ekonomi yang akan meningkat setiap tahunnya.

f. Secara berkala melakukan evaluasi, seleksi, dan pengembangan kerjasama dengan pemasok lama maupun baru.

\section{SARAN}

1. Bagi katering

a. Pemilik katering dapat mendaftarkan usahanya agar mendapatkan sertifikat Laik Higiene Sanitasi Makanan

b. Penjamah makanan dapat lebih memperhatikan personal higiene saat mengolah makanan untuk menghindari pencemaran makanan

c. Pemilik katering dapat menerapkan rekomendasi Strategi Pengembangan terhadap Pengolahan Makanan katering di Kecamatan Simokerto Surabaya

2. Bagi Puskesmas

a. Perlu dilakukan pengawasan rutin pada pengolahan makanan di katering kecamatan Simokerto Surabaya

b. Perlu adanya penyuluhan terkait keamanan pangan dan pengolahan makanan yang baik dan benar di katering kecamatan Simokerto Surabaya

3. Bagi Peneliti Selanjutnya Dapat digunakan sebagai bahan referensi dan bahan pertimbangan untuk dilakukan penelitian dengan metode Analisis yang berbeda. 
DAFTAR PUSTAKA

Amaliyah, Nurul. Januari 2017. Penyehatan Makanan dan Minuman. Yogyakarta, Deepublis

Armiwati, Melly. 2017. Hubungan antara pengolahan makanan dan Fasilitas Sanitasi dengan Angka Kuman pada makanan(Siap Saji) di Kantin Kampus Kota Pontianak. Pontianak. Jurnal Mahasiswa dan Penelitian Kesehatan. diakses pada $26 \quad$ Oktober 2018

Arisman, 2009, Keracunan Makanan: Buku Ajar Ilmu Gizi. Jakarta: ECG

Aspuah, Siti. 2013. Kumpulan Kuesioner dan Instrumen Penelitian. Yogyakarta, Nuha Medika

Anisatul, Auliyah, 2016. Pengaruh Pengolahan Makanan Terhadap Kualitas Makanan di Hotel Aston Rasuna. Jakarta. Jurnal Hospitality dan Pariwisata.diakses Januari 2019 https://journal.ubm.ac.id/index.p hp/hospitalitypariwisata/article/vi ewFile/906/802

Chandra, B. 2006. Pengantar Kesehatan Lingkungan.

Penerbit Buku Kedokteran.

Jakarta, ECG

Departemen Kesehatan Republik Indonesia. 2001. Kumpulan Modul Kursus Penyehatan Makanan bagi Pengusaha Makanan dan Minuman.

Jakarta, Yayasan PESAN
Diktat Petunjuk Praktikum Mikrobiologi Lingkungan.2017.Jurusan Kesehatan Lingkungan.

Politekknik

Kesehatan Surabaya.

Dinas Kesehatan.2016.Laporan Tahunan Dinas Kesehatan Kota Surabaya 2016'

Febria A, dkk. 2009. Hygiene dan Sanitasi pada Pedagang Makanan Jajanan Tradisional di Lingkungan Sekolah Dasar di Kelurahan Demang Lebar Daun Pelembang. Kota Palembang. Jurnal Penelitian Hygiene Sanitasi. Diakses Juni

2019 eprints.unsri.ac.id

Haryanti E, Retna D, 2017. Buku ajar Pengembangan Usaha Kreatif Olahan hasil pertanian melalui Analisis SWOT. Surabaya. PT. Revka Petra Media

Hidayat, A.Aziz Alimul. 2017. Metodologi Penelitian

Keperawatan dan Kesehatan. Jakarta, Salemba Medika

Hutasoit, Togar, 2018. Tingkat Hygiene Penjamah Makanan di Pelabuhan Kelas I Medan dan Faktor yang Mempengaruhi. Abstrak Jurnal Ilmu Kesehatan Masyarakat Universitas Sari Mutiara Indonesia. diakses Januari 2019 